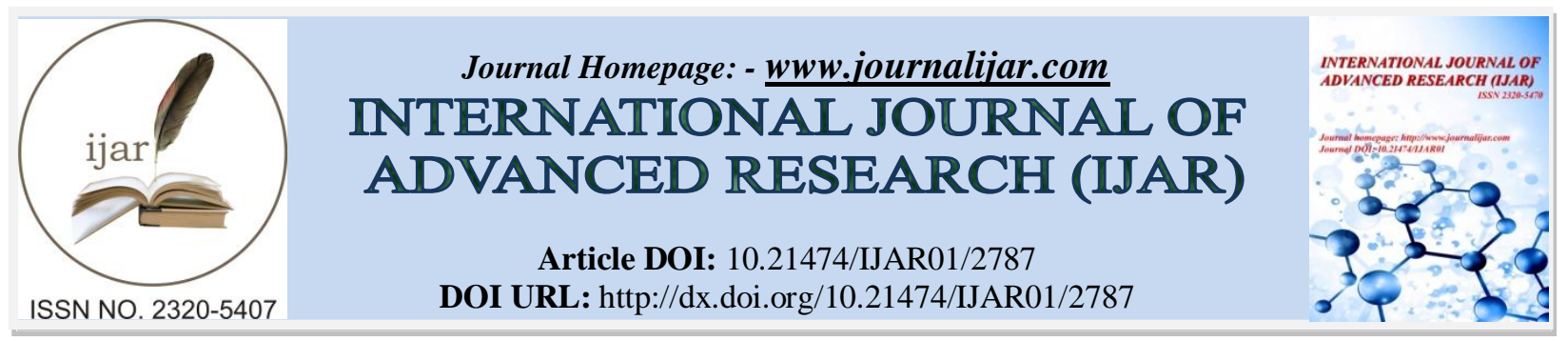

RESEARCH ARTICLE

\title{
DIVERSITY, COMPTABILITY AND NITROGEN FIXATION OF WILD LEGMES RHIZOBIA.
}

Tagelsir Hassan Mohamed Ahmed* and Rabab Mohamed Idriss Musa.

Faculty of Science and Technology, Shendi University. Sudan.

\section{Manuscript Info}

Manuscript History

Received: 15 November 2016

Final Accepted: 17 December 2016

Published: January 2017

\section{Abstract}

The study aims at isolation, identification and preservation of rhizobia isolated from wild legumes and further to test their ability to fix nitrogen with their homologous crop legumes.

A field survey was carried out in Gezira State and Shendi area for the purpose of collecting samples of wild legumes for isolation and identification of their associated rhizobia. Rhizobium strains were isolated using YEMA media and presumptive test were carried out .Seedlings of some leguminous plants representing the main crossinoculation groups were inoculated with isolates from the wild legumes.

The result showed that all collected wild legumes were found to bear nodules on their roots. Some isolates were found to be fast-growing and acid producing rhizobia while others were found to be slowgrwoing and alkaline. The cross inoculation classification of the isolates showed that isolates from Phaseolus trilobus plants can be grouped with Rhizobium leguminosarum bv.Viceae and Rhizobium spp. Isolates from Sesbania sesban and Indigofera articulata can be grouped with Rhizobium leguminosarum bv. Viceae, Rhizobium leguminosarum bv. Phaseoli and Rhizobium spp.

None of the isolates can be grouped with Rhizobium leguminosarum bv. Trifoleae, Bradyrhizobium lupinus or Bradyrhizobium japonicum. It was also noticed that all isolates formed nodules on roots of Vigna unguiculata and they are belonging to the miscellaneous cowpea group.

All of the RAPD primers gave amplification products and they were all reproducible. The most relative isolates were SH1 and ENRRI23 with 73\% similarity; while the most distant were ENRRI21 and TAL380 with similarity percentage of $26 \%$.

Copy Right, IJAR, 2016,. All rights reserved.

\section{Introduction:-}

Wild legumes (herb or tree) are widely distributed in arid regions and actively contributed to soil fertility in these environments. These legumes in arid regions are subject to severe environmental conditions. They have a great variation in nodulation and nitrogen fixation in respect to site and locality. N2 fixing activity and tolerance to drastic conditions may be higher in wild legumes than in crop legumes. Oref. 
A great deal of Rhizobium research has been traditionally devoted to cultivated species, for which the rhizobial microsymbionts have been thoroughly characterized and described (Thies et al., 2001). In contrast, little attention has been dedicated to the root-nodule symbionts of truly wild legumes.intended as those whose ecology is for the most part independent of human action or carry-over. Although there have been some surveys of 'wild' rhizobia, there has been little systematic comparison of the symbionts of wild and cultivated legumes, nor between populations in cultivated and uncultivated soils (Mutch, et al., 2004).

The rhizobia from wild legumes are expected to be adapted to environmental conditions like their symbiont plants. Accordingly, these rizobia can serve as adaptive inoculant rhizobia if they prove to be highly effective in nitrogen fixation with their homologous crop legumes).

The diversity of rhizobia in a particular soil may be influenced by the method of its isolation. Several arrays of techniques are used for detecting and describing rhizobial diversity. These are host range, comparative growth in culture, intrinsic antibiotic resistance, tolerance in $\mathrm{pH}$, and salt. These are among the most common methods that are considered as phenotypic characters and are used primarily to study rhizobial diversity (Maatallaah et al., 2002). The size, shape, color and).

Modern molecular tools which are more preferred to phenotypic methods can also be used to evaluate the specificity of the stains (Thies et al., 2001). Some of these molecular tools employed for rhizobial diversity identification includes: plasmid profiling (Broughton et al., 1987), restriction fragment length polymorphism (RFLP) (Odee et al., 2002), polymerase chain reaction based techniques (PCR) (Richardson et al., 1998).

\section{Materials and Methods:-}

The study was conducted in the Faculty of Science and Technology, Shendi University,Sudan. Five Rhizobium strains were used throughout this study. Foue strains were obtained from The Biofertilization Department, Environmental, Natural Resources and Desertification Research, Institute Khartoum, Sudan. The $5^{\text {th }}$ strain (Shendi S1) was isolated from Sesabania plant grown in Shendi. The source and classification of Rhizobium and Bradyrhizobium strains is shown in table (1).

\section{Morphological Characteristics:-}

The morphological characteristics of the isolates were determined according to Lupwayi and Haque (1994). A loopful of rhizobial isolates from $48 \mathrm{hrs}$ old broth culture was inoculated by streak plating onto YEM Agar and incubated at $28 \pm 20 \mathrm{C}$ for 3 -5days. After 5 days, colony diameter and morphology, colony texture were recorded.

Gram Staining The gram staining technique and motility test were done according to Benson (1994). Biochemical and Physiological characteristics The biochemical and Physiological tests were carried out in growth medium at $28 \mathrm{oC}$ for 48 hours incubation. All the tests were carried out with three replicates.

Acid-base production To determine the ability of the rhizobial isolates to produce acid or alkaline in the medium, YEMA containing bromothymol blue $(0.025 \mathrm{w} / \mathrm{v})$ was used. After the incubation of $72 \mathrm{~h}$ at $28=10 \mathrm{C}$, the $\mathrm{pH}$ changes was scored on the basis of color change of the medium (Chen and Lee,2001).

Oxidase test A few drops of freshly prepared oxidase reagent was added on a piece of filtered paper in a clean Petri plate. Using a glass rod, a colony of the isolate was smeared on the filter paper and the paper was observed for any change in the colors of the reagent (Benson, 1994).

Catalase test A thick growth of the test culture was immersed in $3 \mathrm{ml}$ of $3 \% \mathrm{H} 2 \mathrm{O} 2$ solution with the help of a sterile glass rod. Active bubbling within a few seconds showed a positive catalase activity (Benson, 1994).

\section{Growth rate reaction:-}

A measurement was done by using spectrophotometer to measure growth rate of bacteria for six days.

\section{Phsophorus Solubilization:-}

A single colony of rhizobial strains was streaked on pikovskaia medium containing tricalcium phosphate (Pikovskaia et al.,1948) and incubated at $28 \pm 1^{\circ}$ for 3-5 days. The plates were observed for clear P-zone formation around colonies. 


\section{Inoculation test:-}

A pot experiment was carried out at the Faculty of Science and Technology, Shendi University to study the nodulation of crop legumes (Beans, Kidny peas, Lupin and Bake) by the strains isolated from wild legumes.

Six samples of each crop were replicated four times. Five out of the six samples were injected each with one specific inoculant (strains isolated from wild legumes), while the sixth sample being control. complete Randomized

Six seeds were sown per plastic bag. After the seedling had reached $10-15 \mathrm{~cm}$ in length they were thinned to 3 seedlings per bag. The bags were watered daily in order to maintain the moisture at approximately $75 \%$ of the field capacity.

Inoculation was done aseptically 10 days after sowing.

Five $\mathrm{ml}$ of the broth media were injected by a sterile disposable syringe.

At harvest, nodules number, nodules dry weight, Dry shoot and roots were measured.

\section{Molecular Characterization of Rhizobium:-}

\section{Genomic DNA Extraction:-}

DNA extraction from isolates was done according to the boiling centrifugation method reported by Miller (1972). A single colony was grown over night at $28^{\circ} \mathrm{C}$ in YEM broth. Bacterial cell were precipitated by a centrifugation at $13000 \mathrm{rpm}$ for 10 minute in a micro-centrifuge (Sanyo). The supernatant was discarded and the pellets were resuspended in $500 \mathrm{ml}$ deionized water. The suspension was boiled for 10 minutes in a water bath and then immediately cooled on ice. Extracted DNA was then stored refrigerated until used.

\section{Agarose gel electrophoresis of the extracted DNA:-}

The extracted DNA was electrophoresed in $1.5 \%$ agarose gel $[0.75 \mathrm{~g}$ agarose dissolved in $50 \mathrm{ml}$ of $1 \mathrm{x}$ TBE buffer (0.089 mol/L Tris-borate, and 0.002mM EDTA, $\mathrm{pH} 8.00)$. Then $2 \mu \mathrm{l}$ of ethidium bromide (10 mg/ml) were added Prior to casting the gel, the comb was adjusted and the gel was poured (making sure that there were no bubbles). While the gel was solidifying, DNA mixtures were prepared for electrophoresis as follows: $1 \mu \mathrm{l}$ of each DNA sample was transferred to a clean Eppendorf tube and $3 \mu$ l of loading dye (bromo phenol blue dye) was added to the DNA sample. The content was mixed several times using a micropipette. The comb was removed with gentle back and forth motion and the gel was then immersed in 1x TBE buffer. The buffer was added until it reached a level approximately 3-5 mm above the gel surface. The sample mixtures were loaded into the wells using plastic-tipped micropipettes. $1 \mathrm{~Kb}$ ladder (Invitrogen) was used as a molecular weight marker. The apparatus (Habaib, U.K, 9H $310083)$ was closed and the power was turned on, the voltage was adjusted to $75 \mathrm{~V}(400 \mathrm{~mA})$ and the running was continued without cooling for 20 minutes after which the gel was visualized under trans illumination cabinet (Model TM-10E, Uvitec. Product) and image was captured and photographed. Extracted DNA was then stored refrigerated until used as a template for PCR amplification.

\section{Polymerase chain reaction $(\mathrm{PCR})$ :-}

For genetic diversity studies four RAPD primers were used to amplify the genomic DNA. The primers were purchased from Gene link, Inc. and Operon Tech., NY 10532. These were 10 oligonucleotide OPC9 primer (CTCACCGTCC), OPY14 (GGTCGATCTG),opl 18 (ACCACCACC) and opr 10(CCAATCCA).

PCR amplification reactions were carried out in a total volume of $20 \mu 1$. Each PCR mixtures contained (Final concentration): 5X FIRE Pol PCR Master Mix (Ready to load), 5 X reaction buffer $\left(0.4 \mathrm{M}\right.$ Tris-HCL, $0.1 \mathrm{M}\left(\mathrm{NH}_{4}\right)$ $\mathrm{SO}_{4}, 0.1 \% \mathrm{w} / \mathrm{v}$ Tween 20), $12.5 \mathrm{Mm}$ dNTPs, $50 \mathrm{ng}$ of the primer under test, $1 \mathrm{U}$ Taq polymerase and $20 \mathrm{ng}$ template DNA.

The amplification program used consisted of one cycle at $94^{\circ} \mathrm{C}$ for $5 \mathrm{~min}$, followed by 35 cycles of initial denaturation at $94^{\circ} \mathrm{C}$ for $1 \mathrm{~min}$, annealing at $32^{\circ} \mathrm{C}$ for $3 \mathrm{~min}$, extension at $72^{\circ} \mathrm{C}$ for 2 min and a final extension step at $72^{\circ} \mathrm{C}$ for $10 \mathrm{~min}$.

\section{Results and Discussion:-}

Table 2 showed the growth rate of the rhizobial isolates tasted .Three of the 5 rhizobia under test performed fast growing rate in $(3-5)$ days to form separate colonies these were Crotalaria senegalesis, Desmodium dichotomm 
and Clitorea ternata. It was understood that the fast growing nodule bacteria belongs to the genus Rhizobium were the slow growing ones belong to the Bradyrhizobium. Sesabania sesban belongs to Isorhizobium although it is a slow growing bacteria.

Progress in bacteria growth rate was observed during the second day - fourth day, while deterioration observed at fifth and sixth days. It was reported that the fast growing rhizobia belongs to rhizobium and the slow growing ones were bradyrhizobium (Hiaty 1990).

Acid base production reaction (Bromothymol) Crotalaria senegalensis, Desmodium dichotomum and Clitoria ternate changed the growth medium to acidic one were as the other two changed the medium to alkaline one (table 2). It was reported by many researche workers the acid producing root nodule bacteria were classified as Rhizobium and the alkali producing ones were Bradyrhizobium.

The acid producing Rhizobium changed the color of the growing medium when Bromothymole blue added to the broth culture to yellow color producing acids. The alkaline producing Bradyrhizobium changed the color of the medium from blue to dark blue (Jordan, 1984)

Table (3) showed the some biochemical tests of the collected strain from wild legumes.

All the strains were found to be gram negative, catalase positive and solubilize phosphorus except strain SHS1, which was isolated from Sesbania sesban which did not solubilize phosphorus.

\section{Inoculation test:-}

As shown in Table (4) cross inoculation of legumes by the strains isolated from wild legumes it was clear that Vicia faba formed nodules by most of the strains, Phaseolus vulgares only formed nodules by strain $\mathrm{SHS}_{1}$ and non of the strains formed nodules in Trifolium sp . A previous study of Rhizbium isolates indicated that one isolate had the ability to nodulate both alfalfa and common bean (Eardly et al ,. 1985).

The presence of isolates from wild legumes cross-inoculating Phaseolus vulgaris is an important finding since it is known that this crop is poorly nodulated and rarely forms effective symbiosis with rhizobia (Herridge and Bergersen, 1988). Isolates from the wild legumes might serve as a solution for this problem and might prove to be effective in nitrogen fixation with Phaseolus vulgaris. This necessitates extensive research on the compatibility of isolates from wild legumes with leguminous crops and their ability to form effective symbiosis with their homologous crop .

The result of the experiment showed that some of the isolates belong to more than one cross-inoculation group. This finding reflects the weakness of the cross-inoculation classification of rhizobia which has been criticized by many researchers (Segovia et al; 1993). This entails that other systems of classification should be studied and adopted for the identification and classification of rhizobia.

Molecular Characterization of Rhizobium:-

The 9 isolates were amplified using 4 different Operon RAPD primers. The primers were: OPC9, OPL18, OPR10 and OPY14.

$>$ All of the RAPD primers gave amplification products and they were all reproducible.

$>$ A total of 141 fragments were detected for the 9 isolates representing 25 different loci with $100 \%$ polymorphism.

$>55.6 \%$ of the 9 isolates (ENRRI21, ENRRI22, USDA209, ENRRI2 and ENRRI8) didn't produce any amplification product with primer OPC9.

$>\quad$ Isolate 2 gave no product with primer OPL18.

$>$ The Similarity indices were calculated using Jaccard's coefficient.

$>$ The most relative isolates were SHS1 and ENRRI23 with 73\% similarity; while the most distant were ENRRI21 and TAL380 with similarity percentage of $26 \%$.

$>$ According to the similarity indices, the nine samples were grouped into three clusters each containing three isolates. Cluster 1 includes ENRRI23, SHS1 AND ENRRI3; Cluster 2 contained ENRRI22, ENRRI2 and TAL380 while Cluster 3 includes ENRRI21, USDA209 and ENRRI8. 
The results of PCR experiment are recorded in table 6and depicted in figure number 8 as well. In figure 8 the uppermost cluster comprises the SH1, ENRRI3 and ENRRI23 isolates which are most genetically compatible. As the similarity reaches around 0.71 which gives rise to a far extent of genetically compatibility .

The RAPD technique was used to detect the compatibility between 9 isolates of rhizobia used in this study, which analysis clear the most relative isolates were SH1 and ENRRI23, this similarity could be attributed to compatible genetically characteristics. While the most distant were TAL380 and ENRRI21 which may be underlying to fewer shared genetically characteristics.

Table 1:- source and classification of rhizobia

\begin{tabular}{|l|l|l|l|l|l|}
\hline No & Host Plant & Short name & Local name & Subfamily & $\begin{array}{l}\text { Area } \\
\text { collection }\end{array}$ \\
\hline 1 & $\begin{array}{l}\text { Crotalaria } \\
\text { senegalensis }\end{array}$ & ENRRI 3 & Fartaga & Papilionoidea & Gezira \\
\hline 2 & Phaseolus trilobus & ENRRI 21 & Phillipsara & Papilionoidea & $"$ \\
\hline 3 & $\begin{array}{l}\text { Desmodium } \\
\text { dichotomum }\end{array}$ & ENRRI 22 & Abu-Areeda & Papilionoidea & \\
\hline 4 & Clitorea ternate & ENRRI 23 & Clitoria & Papilionoidea & " \\
\hline 5 & Sesbania sesban & SHS 1 & Sesban & Papilionoidea & Shendi \\
\hline
\end{tabular}

Table 2:- growth rate and growth reaction of Rhizobia

\begin{tabular}{|l|l|l|l|l|}
\hline No & Host Plant & Short name & Growth rate & $\begin{array}{l}\text { Growth reaction } \\
\text { bromothymol }\end{array}$ \\
\hline 1 & Crotalaria senegalensis & ENRRI 3 & Fast & Yellow / Acidic \\
\hline 2 & Phaseolus trilobus & ENRRI 21 & Slow & Blue / Alkaline \\
\hline 3 & Desmodium dichotomum & ENRRI 22 & Fast & Yellow / Acidic \\
\hline 4 & Clitorea ternate & ENRRI 23 & Fast & $"$ \\
\hline 5 & Sesbania sesban & SHS 1 & Slow & Blue / Alkaline \\
\hline
\end{tabular}

Table 3:- biochemical characteristics of Rhizobium. strains

\begin{tabular}{|l|l|l|l|l|l|}
\hline No & Host Plant & Short name & $\begin{array}{l}\text { Gram } \\
\text { Stain }\end{array}$ & Catalase test & Phosphorus sol \\
\hline 1 & Crotalaria senegalensis & ENRRI 3 & - Ve & + & + \\
\hline 2 & Phaseolus trilobus & ENRRI 21 & - Ve & + & + \\
\hline 3 & Desmodium dichotomum & ENRRI 22 & - Ve & + & + \\
\hline 4 & Clitorea ternate & ENRRI 23 & - Ve & + & + \\
\hline 5 & Sesbania sesban & SHS 1 & - Ve & + & - \\
\hline
\end{tabular}

Table 4:- Nodulation and cross inoculation

\begin{tabular}{|l|l|l|l|l|l|}
\hline No & Host Plant & Source & Vicia faba & Phaseolus vulgaris & Trifoliam SP \\
\hline 1 & Crotalaria senegalensis & Gezira & - & - & - \\
\hline 2 & Phaseolus trilobus & $"$ & + & - & - \\
\hline 3 & Desmodium dichotomum & $"$ & - & - & - \\
\hline 4 & Clitorea ternate & $"$ & + & - & - \\
\hline 5 & Sesbania sesban & Shendi & + & + & - \\
\hline
\end{tabular}


Table 5:- Similarity matrix between different tested isolates of Rhizobium constructed from RAPD - PCR banding pattern

\begin{tabular}{|l|l|l|l|l|l|l|l|l|l|}
\hline & SHS1 & ENRRI3 & ENRRI21 & ENRRI23 & ENRRI22 & USDA209 & ENRRI2 & TAL380 & ENRRI8 \\
\hline SHS1 & 1.00 & & & & & & & & \\
\hline ENRRI3 & 0.71 & 1.00 & & & & & & & \\
\hline ENRRI21 & 0.41 & 0.42 & 1.00 & & & & & & \\
\hline ENRRI23 & 0.73 & 0.70 & 0.53 & 1.00 & & & & & \\
\hline ENRRI22 & 0.52 & 0.35 & 0.30 & 0.38 & 1.00 & & & & \\
\hline USDA209 & 0.46 & 0.48 & 0.53 & 0.43 & 0.43 & 1.00 & & & \\
\hline ENRRI2 & 0.57 & 0.45 & 0.42 & 0.48 & 0.72 & 0.55 & 1.00 & & \\
\hline TAL380 & 0.65 & 0.48 & 0.26 & 0.50 & 0.57 & 0.38 & 0.62 & 1.00 & \\
\hline ENRRI8 & 0.52 & 0.56 & 0.53 & 0.43 & 0.42 & 0.59 & 0.47 & 0.30 & 1.00 \\
\hline
\end{tabular}
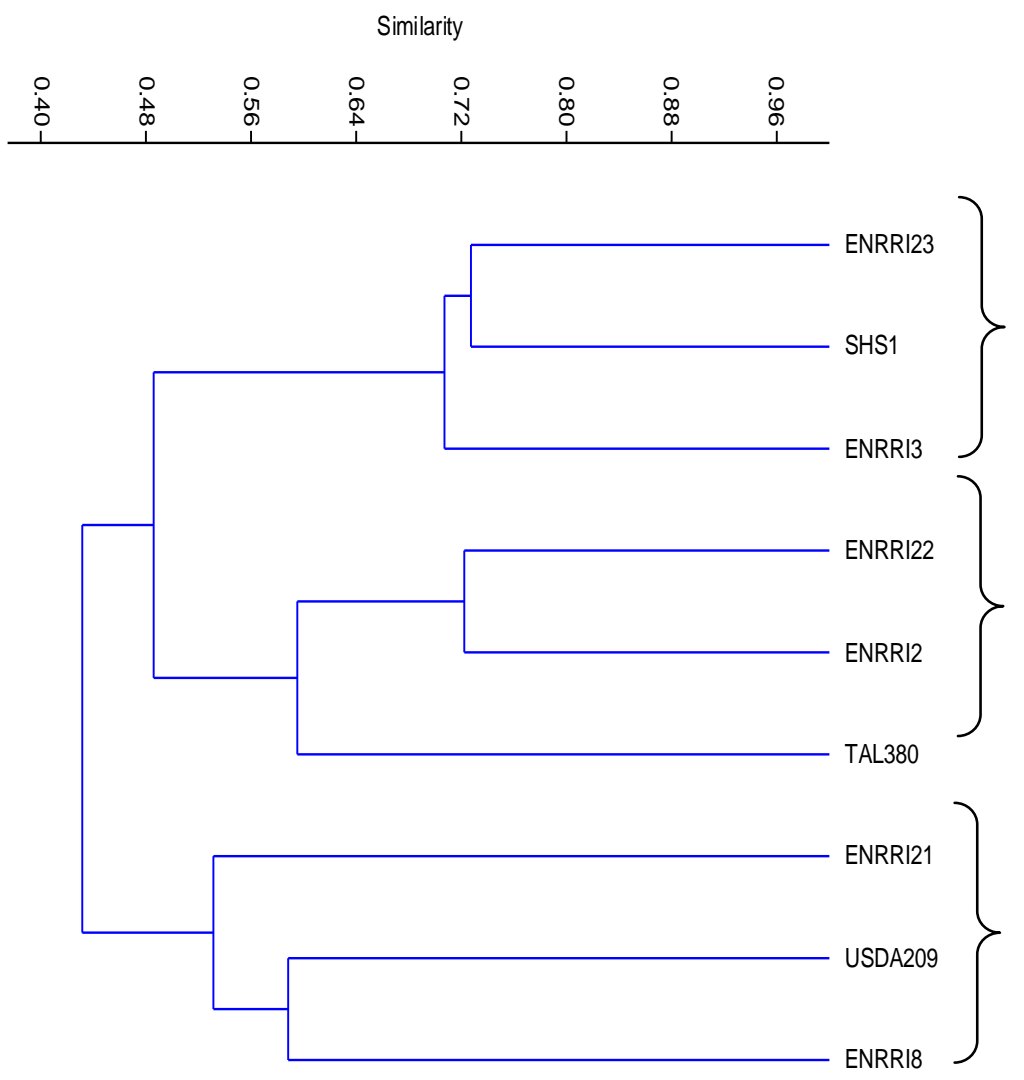

Figure 1:- Dendrogram tree of Rhizobium strians isolated from wild legumes based on RAPD - PCR 


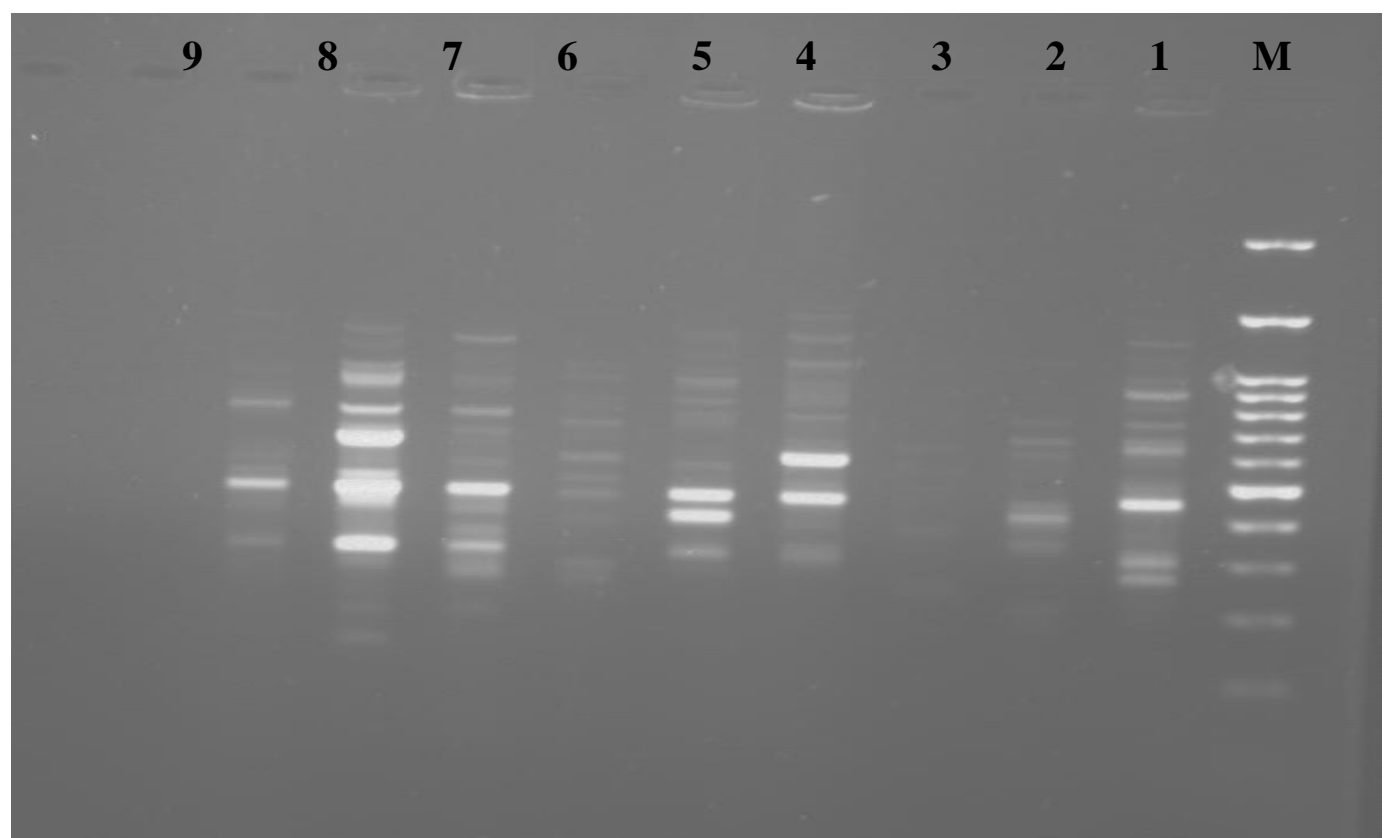

Figure 2:- .RAPD product of primer opr 10 of Rhizobium strains

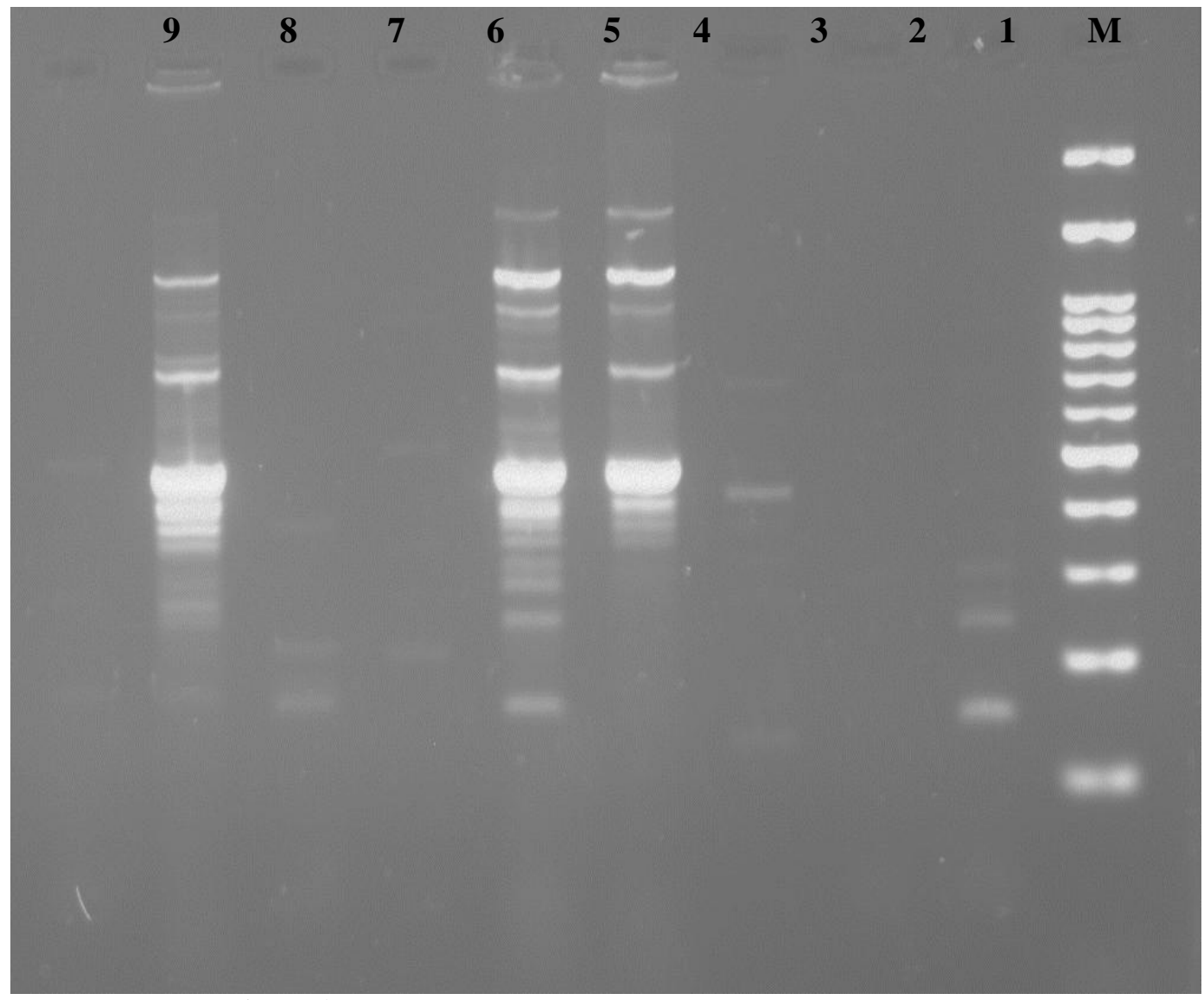

Figure 3:- RAPD product ofprimer opl18 of Rhizobium strains 


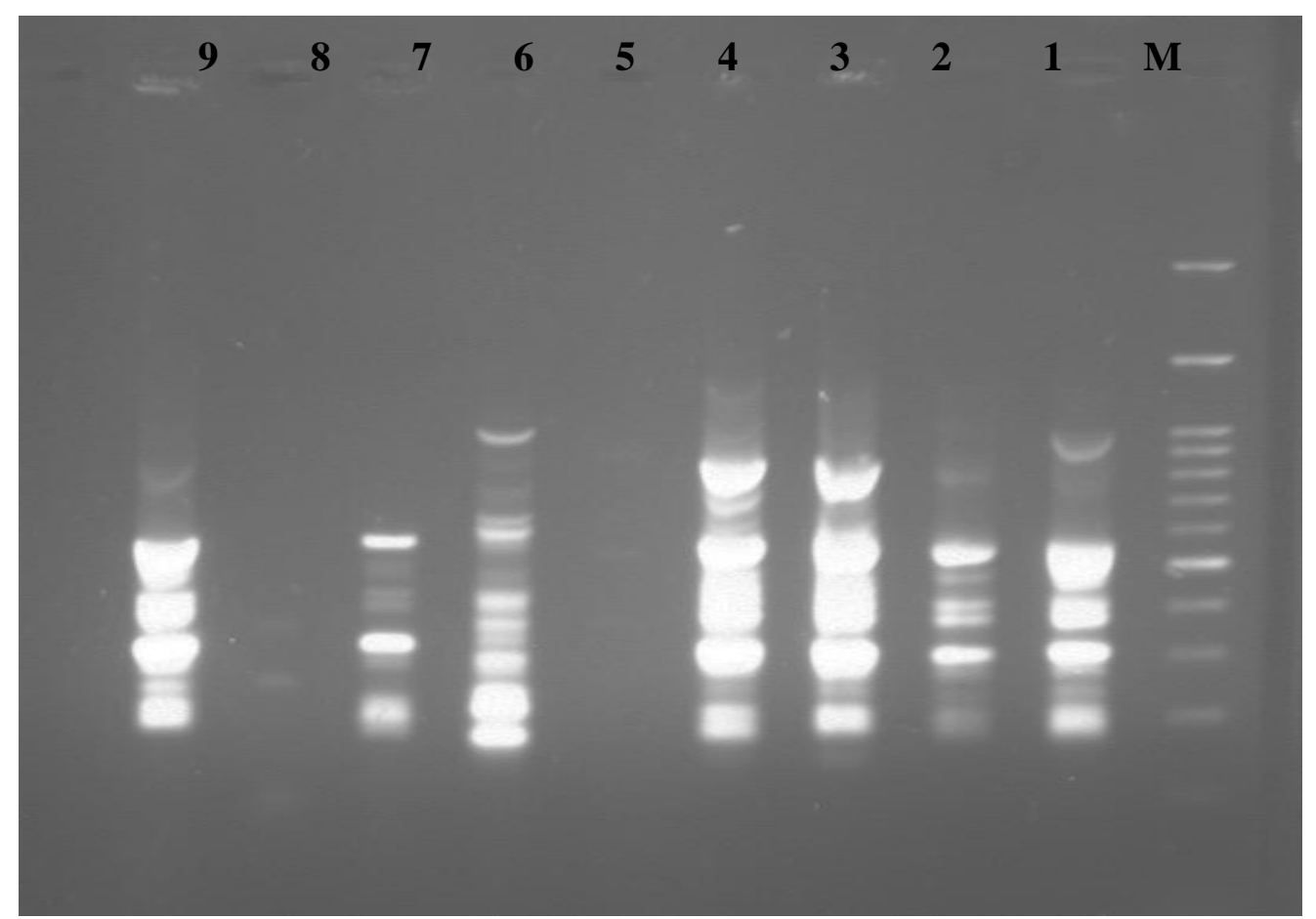

Figure 4:- .RAPD product of primer opy14 of Rhizobium strains

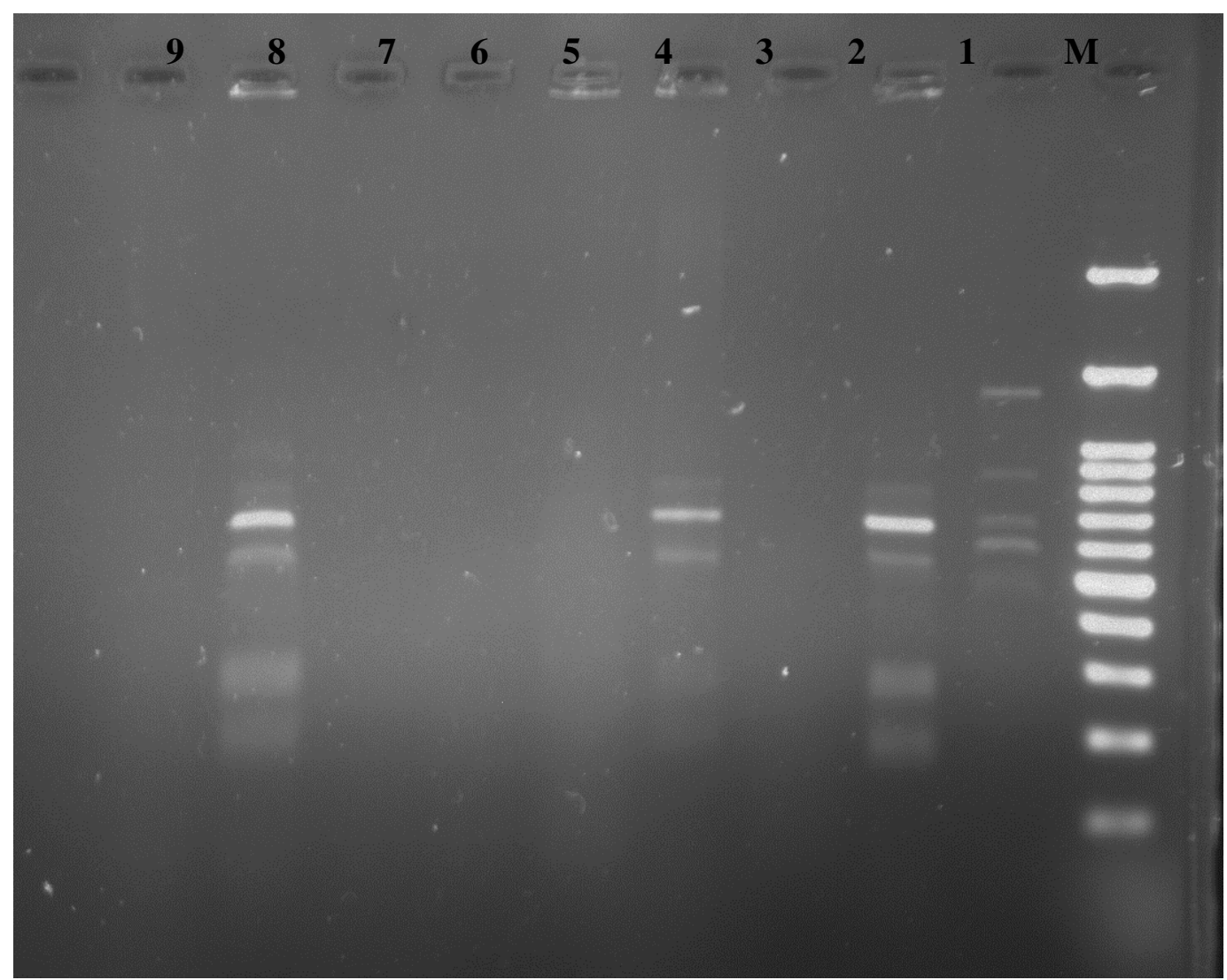

Figure 5:- RAPD product of primer opc9 of Rhizobium strains 


\section{References:-}

1. Benson, H. J., (1994). Microbiology application, Complete Version. $\quad$ Laboratory manual in general microbiology, 8th edition W.C. Brown Publishers, Dubuque, Mebourn, Oxford.

2. Broughton, W. J., Samery, U. and Stanley, J. (1987). Ecological genetics of Rhizobum meliloti: symbiotic plasmid transfer in the Medicago sativa rhizosp here. FEMS. Microbiol. Letters 40: 251-255.

3. Eardly, B, D.,Hannaway, D, B, and Bottomley, P, J, (1985).

4. Characterization of rhizobia from ineffective alfalfa nodules; ability to nodulate bean plants (Phaseolus vulgaris (L.) Savi.J, of Appl, Environ, Microbiol.50: 1422-1427.

5. Herridge, D. F. and Bergersen, F. J. (1988). Symbiotic nitrogen fixation. In: Advances in Nitrogen Cycling in Agricultural Ecosystems (ed. J. R. Wilson) pp. 45-52.

6. Jordan, D. C. (1984). Family III. Rhizobiaceae. In: Bergey s Manual of Systemaic Bacteriology, pp. 234254, (Krieg, N. R. and Holt, J. G. $\quad$ eds). The Williams and Wilkins, Baltimore.

7. Lupway, N. Z. and Haque, I. (1994). Working document: legume- rhizobium technology manual. Environmental science division international livestock center for Africa, Addis Ababa, Ethiopia. PP 1-40.

8. Maatallah, J., Berraho, E. B., Sanjuan, J. and Lunch, C. (2002). Phenotypic characterization of rhizobia isolates from chickpea (Cicer arrientium growing in Morroccan soils. Agronomic. 22: $\quad 321-329$.

9. Miller,(1972).Experiment in Molecular Genetics.Front. Cover. Jeffry H. Miller.Cold spring Harbr Laboratory, 1972,-Science-466 pages.

10. Mutch et al., 2004.Pesticide Biotransformation and Dispostion. Emest Hodgson.

11. Odee, D. W., Haukka, K., Mclnroy, S. G., Sprent, J. I, Sutherland, J. M. $\quad$ and Young, J. P W. (2002). Genetic and symbiotic characterization of rhizobia isolated form free. and herbaceous legumes grown in soils from ecologically diverse sites in Kenya. Soil biol. Biochem. 34: 801-811.

12. Pikovskaia et al .,(1984).First International Meeting on Microbial Phosphate Solubilization.C. RodriguczBarrueco, E.Velazques.

13. Richardson, A.E., Simpson, R. J., Djordjevie, M. A. and Rolfe, B. J. (1998). Expression of nodulation genes in Rhizobium leguminosarum biovar trifolii affected by low $\mathrm{pH}$ and by $\mathrm{Ca} 2+$ and $\mathrm{Al}$ ions. Appl. 2541-2548.

14. Segovia, L., Peter, J., Young, W. and Martinez-Romero, E. ( 1993).Reclassification of American Rhizobium leguminosarum bv. Phaseoli type 1 strain as rhizobium etli sp. Nov. Interl. J. of System. Bacteriol. 43(2):374-377.

15. Thies, J. E., Holmes, E. M. and Vachot, A. (2001). Application of molecular Techniques to studies in rhizobium ecology: a review Aust. J. Exp. Agr.

16. Zahran,H. H. (2001). Rhizobia of Wild Legumes: diversity, taxonomy, ecology, nitrogen fixation and biotechnology. Journal of Biotechnology.91: 143-153. 